\title{
Carbonylative Cross-Electrophile Coupling Between Aryl Bromides and Aryl Triflates Enabled by Palladium and Rhodium Cooperative Catalysis
}

\author{
Xue Xiao, a* Gang Chen, a* Xuemei Zhang, a Søren Kramer, ${ }^{*}$ and Zhong Liana* \\ a Department of Dermatology, State Key Laboratory of Biotherapy and Cancer Center, National Clinical Research Cen- \\ ter for Geriatrics, West China Hospital and West China School of Pharmacy, Sichuan University, Chengdu 610041, P.R. \\ China \\ b Department of Chemistry, Technical University of Denmark, Kemitorvet 207, 2800 Kgs. Lyngby, Denmark.
}

\begin{abstract}
Ketones are among the most useful functional groups in organic synthesis. Here, we report the first carbonylative cross-electrophile coupling reaction that utilize carbon monoxide gas as the carbonyl source. The use of Pd/Rh cooperative catalysis enables the carbonylative coupling of easily accessible aryl triflates and aryl bromides. Unlike all previous carbonylative cross-electrophile coupling reactions, the method does not require addition of a stoichiometric metal reductant.
\end{abstract}

Ketones are among the most versatile functional groups in organic synthesis. Furthermore, they are part of the core skeleton in many natural products and pharmaceuticals. ${ }^{1}$ The tremendous progress in transition-metal-catalyzed carbonylative cross-coupling reactions has made it a powerful strategy for accessing the ketone functionality (Scheme 1a). ${ }^{2}$ These transition-metal-catalyzed reactions require the combination of an electrophilic coupling partner, typically aryl halides or pseudohalides, with a nucleophilic coupling partner, typically a metal-based reagent. Unfortunately, many of these metal-based nucleophiles have limited accessibility and stability, which can place restrictions on the substrate scope and affect the functional group tolerance for these normal cross-coupling reactions.

Due to the potential limitations with normal crosscoupling reactions, recently, significant efforts have been invested in the development of cross-coupling reactions between two electrophilic coupling partners. ${ }^{3}$ Although these cross-electrophile coupling reactions require a stoichiometric reductant, typically $\mathrm{Zn}$ or $\mathrm{Mn}$, it avoids the need for a nucleophilic coupling partner. ${ }^{3-5}$ Nonetheless, achieving selective cross-coupling rather than homo-coupling between two electrophilic coupling partners is challenging. An elegant solution, pioneered by Weix, is the use of cooperative metal catalysis, where different metal catalysts are used to activate the two coupling partners. ${ }^{6}$ In this approach, the two metal catalysts selectively undergo oxidative addition to each of the two different $\mathrm{C}-\mathrm{X}$ bonds. Subsequent transmetallation between the two oxidative addition complexes followed by reductive elimination leads to the desired cross-coupling of the two electrophiles. Finally, the other metal catalyst is reduced back to its starting state by a stoichiometric metal reductant.

Recently, ketone synthesis using cross-electrophile coupling reactions has witnessed significant progress. However, essentially all the developed methods utilize an acyl
Scheme 1. Comparison of Previous Work to This Work

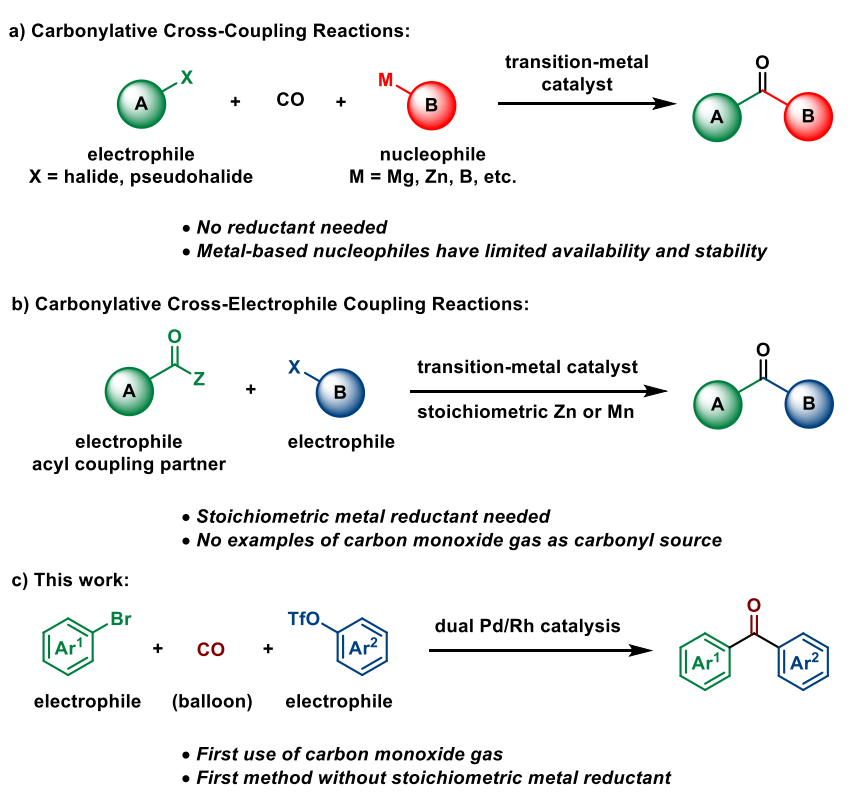

coupling partner instead of carbon monoxide, and they all require stoichiometric amounts of a metal reductant such as $\mathrm{Mn}$ or $\mathrm{Zn}$ (Scheme 1b). ${ }^{7-9}$ There are no reports of carbon monoxide gas as the carbonyl source despite that it is a widely available $\mathrm{C} 1$ building block.

Here, we report the first carbonylative cross-electrophile coupling method that use carbon monoxide as carbonyl source (Scheme 1c). Remarkably, unlike all previous carbonylative cross-electrophile coupling reactions, the method does not require a stoichiometric metal reductant. The developed methodology represents the first example of palladium/rhodium dual metal catalysis in carbonylative cross-electrophile coupling reactions. ${ }^{10}$ Furthermore, the two electrophilic coupling partners used are aryl bro- 
Table 1. Influence of Ligand on Reaction Outcome ${ }^{a}$

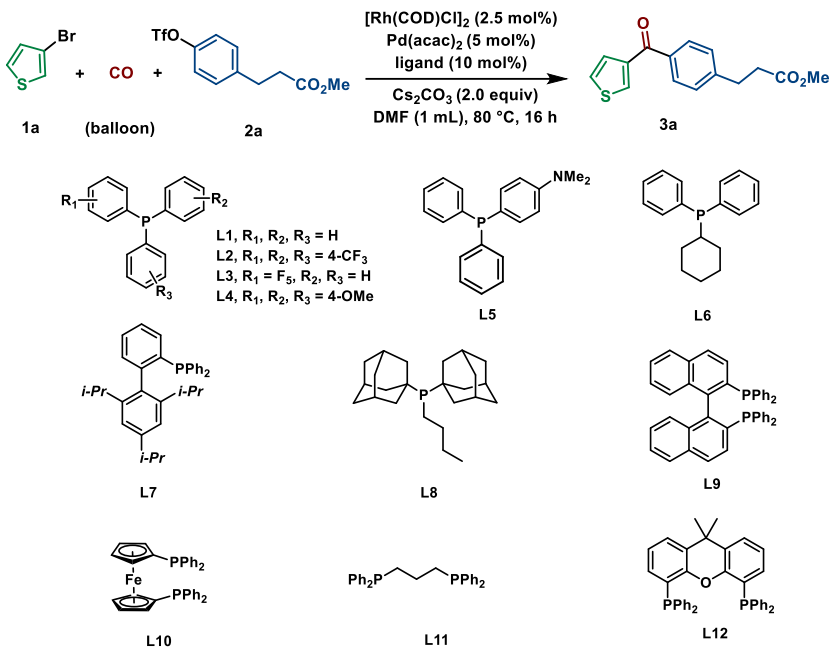

\begin{tabular}{ccc}
\hline Entry & Ligand & ${\text { Yield of } \mathbf{3} \mathbf{a}^{b}}^{b}$ \\
\hline 1 & L1 & $22 \%$ \\
2 & L2 & $0 \%$ \\
3 & L3 & $<1 \%$ \\
4 & L4 & $22 \%$ \\
5 & L5 & $24 \%$ \\
6 & L6 & $19 \%$ \\
7 & L7-11 & $0 \%$ \\
8 & L12 & $19 \%$ \\
\hline
\end{tabular}

a Reaction conditions: $\mathbf{1 a}(0.2 \mathrm{mmol}, 1.0$ equiv), $\mathbf{2 a}(0.2 \mathrm{mmol}$, 1.0 equiv). ${ }^{b} \mathrm{GC}$-yields.

mides and aryl triflates, which are easily accessible from phenols. Both aryl bromides and phenols are very abundant, thus enabling access to a broad range of products with the developed method.
We started the investigation of the carbonylative crosselectrophile coupling using 3-bromothiophene $\mathbf{1 a}$ and aryl triflate $\mathbf{2 a}$ as model substrates under a CO atmosphere (CO balloon). An initial reaction using $\left[\mathrm{Rh}(\mathrm{COD})_{2} \mathrm{Cl}\right]_{2} \quad(2.5$ mol\%), $\mathrm{Pd}(\mathrm{acac})_{2}$ (5 mol\%), $\mathrm{Cs}_{2} \mathrm{CO}_{3}$ (2.0 equiv), and monodentate phosphine $\mathrm{PPh}_{3}(10 \mathrm{~mol} \%)$ in DMF confirmed the prospect of carbonylative coupling between the aryl bromide and aryl triflate (Table 1, entry 1). Encouraged by the initial result, $\mathrm{PPh}_{3}$-derivatives bearing substituents with different electronic properties were examined. While electron-withdrawing substituents on the aryl moiety of the phosphine were detrimental for the reaction (L2-3), electron-donating substituents, such as $\mathrm{OMe}(\mathbf{L} 4)$ and $\mathrm{NMe}_{2}$ (L5), led to comparable or slightly improved yields relative to $\mathrm{PPh}_{3}$ (entries 2-5). The use of a more nucleophilic alkyl diaryl phosphine (L6) did not improve the yield further (entry 6). Other types of commonly used monodentate or bidentate phosphine ligands, such as XPhos (L7), n$\operatorname{BuP}(\mathrm{Ad})_{2}$ (L8), BINAP (L9), dppf (L10), and dppp (L11) did not afford the desired product (entry 7). Besides the $\mathrm{PPh}_{3}$-based ligands, only Xantphos led to the desired product (entry 8). Overall, L5 was identified as the most promising ligand.

Next, different Rh catalysts were examined. The commonly used $\left(\mathrm{PPh}_{3}\right)_{3} \mathrm{RhCl}$ showed better catalytic activity compared to [Rh(COD)Cl] $]_{2}$ (Table 2, entries 1-2). Continuing with $\left(\mathrm{PPh}_{3}\right)_{3} \mathrm{RhCl}$, we found that increasing the amount of aryl triflate $\mathbf{2 a}$ effectively reduced the formation of homocoupling product from $\mathbf{1 a}$ thereby increasing the yield of the desired product (entry 3). Further improvement in yield was achieved by slightly increasing the loading of Rh catalysts and ligand L5 (entry 4). The reaction outcome is highly base dependent (entries 4-7). Although $\mathrm{Cs}_{2} \mathrm{CO}_{3}$ afforded the highest yield, $\mathrm{K}_{2} \mathrm{CO}_{3}$ also led to significant product formation. Other bases, such as $\mathrm{CH}_{3}$ COOCs and $\mathrm{CsF}$, led to poor yields. The solvent also had a large effect on the

Table 2. Optimization of Reaction Conditions ${ }^{a}$

\begin{tabular}{|c|c|c|c|c|}
\hline & $\begin{array}{l}+ \\
+ \\
\text { (balloon) }\end{array}$ & 2a & 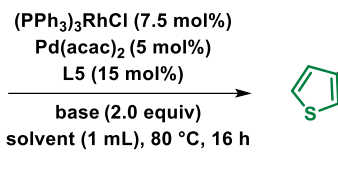 & \\
\hline Entry & {$[\mathrm{Rh}]$} & Base & Solvent & Yield of $\mathbf{3} \mathbf{a}^{b}$ \\
\hline $1^{c}$ & {$[\mathrm{Rh}(\mathrm{COD}) \mathrm{Cl}]_{2}$} & $\mathrm{Cs}_{2} \mathrm{CO}_{3}$ & DMF & $24 \%$ \\
\hline $2^{c}$ & $\left(\mathrm{PPh}_{3}\right)_{3} \mathrm{RhCl}$ & $\mathrm{Cs}_{2} \mathrm{CO}_{3}$ & DMF & $33 \%$ \\
\hline $3^{d}$ & $\left(\mathrm{PPh}_{3}\right)_{3} \mathrm{RhCl}$ & $\mathrm{Cs}_{2} \mathrm{CO}_{3}$ & DMF & $41 \%$ \\
\hline 4 & $\left(\mathrm{PPh}_{3}\right)_{3} \mathrm{RhCl}$ & $\mathrm{Cs}_{2} \mathrm{CO}_{3}$ & DMF & $58 \%$ \\
\hline 5 & $\left(\mathrm{PPh}_{3}\right)_{3} \mathrm{RhCl}$ & $\mathrm{K}_{2} \mathrm{CO}_{3}$ & DMF & $43 \%$ \\
\hline 6 & $\left(\mathrm{PPh}_{3}\right)_{3} \mathrm{RhCl}$ & CsF & DMF & $12 \%$ \\
\hline 7 & $\left(\mathrm{PPh}_{3}\right)_{3} \mathrm{RhCl}$ & $\mathrm{CH}_{3} \mathrm{COOCs}$ & DMF & $0 \%$ \\
\hline 8 & $\left(\mathrm{PPh}_{3}\right)_{3} \mathrm{RhCl}$ & $\mathrm{Cs}_{2} \mathrm{CO}_{3}$ & DMAc & $16 \%$ \\
\hline 9 & $\left(\mathrm{PPh}_{3}\right)_{3} \mathrm{RhCl}$ & $\mathrm{Cs}_{2} \mathrm{CO}_{3}$ & NMP & $31 \%$ \\
\hline 10 & $\left(\mathrm{PPh}_{3}\right)_{3} \mathrm{RhCl}$ & $\mathrm{Cs}_{2} \mathrm{CO}_{3}$ & DMSO & $14 \%$ \\
\hline 11 & $\left(\mathrm{PPh}_{3}\right)_{3} \mathrm{RhCl}$ & $\mathrm{Cs}_{2} \mathrm{CO}_{3}$ & toluene/DMF(1:1) & $79 \%(73 \%)^{e}$ \\
\hline 12 & $\left(\mathrm{PPh}_{3}\right)_{3} \mathrm{RhCl}$ & $\mathrm{Cs}_{2} \mathrm{CO}_{3}$ & toluene/DMF( $4: 1)$ & $50 \%$ \\
\hline 13 & $\left(\mathrm{PPh}_{3}\right)_{3} \mathrm{RhCl}$ & $\mathrm{Cs}_{2} \mathrm{CO}_{3}$ & toluene/DMF(1:4) & $71 \%$ \\
\hline
\end{tabular}

${ }^{a}$ Reaction conditions: 1a $\left(0.2 \mathrm{mmol}, 1.0\right.$ equiv), $\mathbf{2 a}\left(0.28 \mathrm{mmol}, 1.4\right.$ equiv), [Rh] (7.5 mol\%), L5 (15 mol\%). ${ }^{b}$ GC-yields. ${ }^{c}$ Reaction conditions: 1a $\left(0.2 \mathrm{mmol}, 1.0\right.$ equiv), $\mathbf{2 a}\left(0.2 \mathrm{mmol}, 1.0\right.$ equiv), [Rh] (5 mol\%), L5 (10 mol\%). ${ }^{d}$ Reaction conditions: $\mathbf{1 a}(0.2 \mathrm{mmol}, 1.0$ equiv), $\mathbf{2 a}$ $\left(0.28 \mathrm{mmol}, 1.4\right.$ equiv), [Rh] (5 mol\%), $\mathbf{L 5}(10 \mathrm{~mol} \%){ }^{e}$ Isolated yield in parenthesis. 


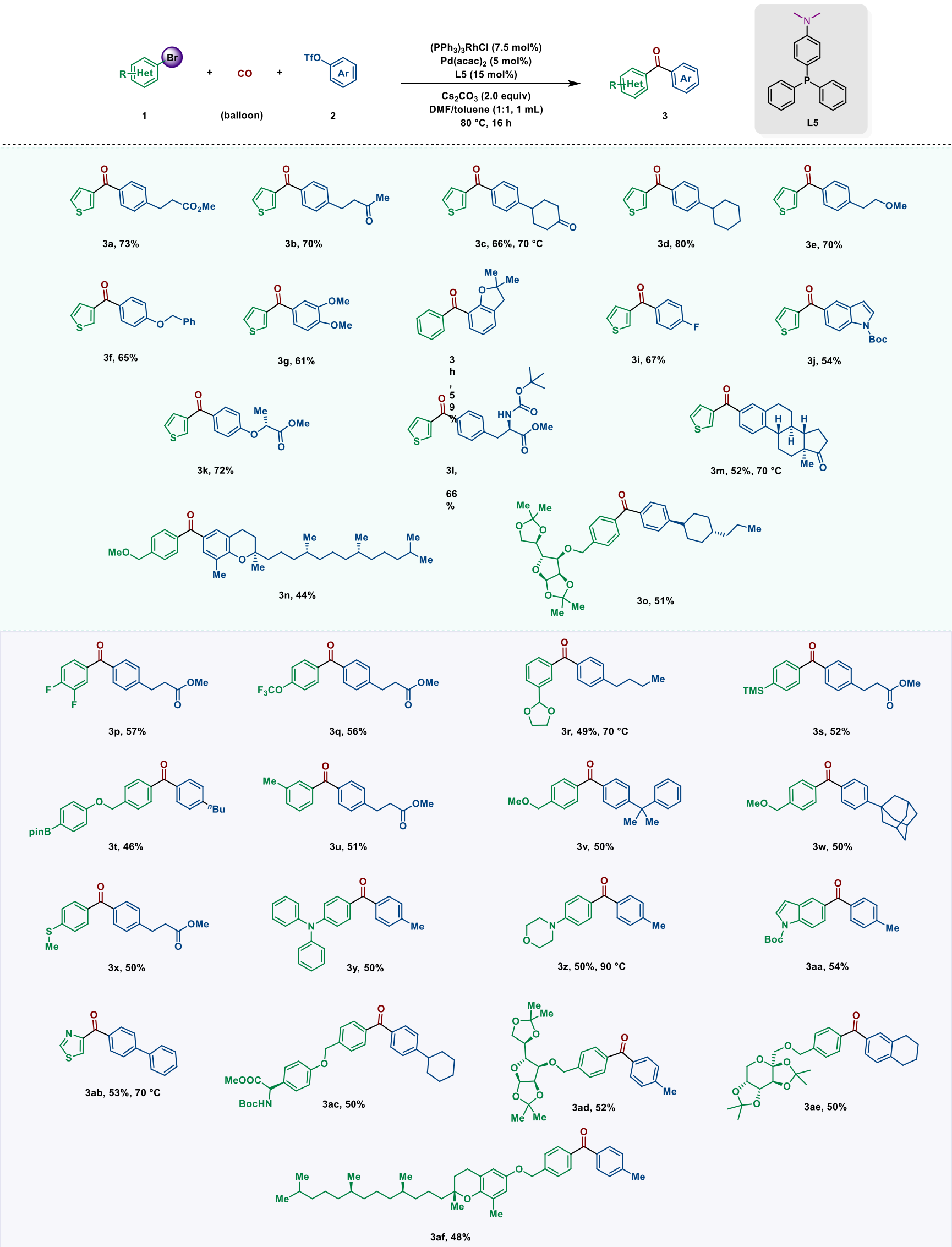

${ }^{a}$ Reaction conditions from Table 2, entry 11, unless otherwise noted. 
reaction outcome, but other pure solvents gave inferior results compared to DMF (entries 8-10). However, a 1:1 solvent mixture of DMF and toluene improved the yield leading to $73 \%$ isolated yield of the desired product (entry 11). Other toluene/DMF ratios gave lower yields (entries 12-13).

After having identified reactions conditions that produce the carbonylative cross-electrophile coupling product in a high yield, a variety of aryl triflates were examined as substrates for this transformation (Scheme 2). Aryl triflates bearing electron-withdrawing groups such as ketone and ester reacted smoothly with 3-bromothiophene 1a delivering the corresponding diaryl ketones (3a-c) in good yields. A cyclohexyl-substituted aryl triflate provided $80 \%$ yield of the desired product 3d. Aryl triflates bearing alkyl or aryl ether groups were also compatible with the transformation (3e-g). Even an ortho-substituted aryl triflate led to the desired ketone $\mathbf{3 h}$ in $59 \%$ yield. Other functional groups such as fluoride and indole as well as a tyrosinederived triflate were also tolerated, and the target products 3i-l obtained in good yields. Encouraged by these results, we applied the carbonylative cross-electrophile coupling to more complex aryl triflates derived from estrone, $\delta$-tocopherol, and allose. Pleasingly, they all provided the desired products (3m-3o).

To further explore the substrate scope, we investigated a series of aryl bromides (Scheme 2). In addition to 3bromothiophene, bromobenzene derivatives are also suitable substrates for the carbonylative coupling process. A variety of functional groups are tolerated on the aryl bromide, such as fluoride, $\mathrm{OCF}_{3}$, and an acetal (3p-r). Also, substrates bearing a trimethylsilyl group and a boronic ester are compatible with the transformation, thus providing useful handles for further functionalizations (3s-t). Substrates containing alkyl substituents, ether, or thioether groups afforded the desired products with no change in efficiency (3u-x). Amine functional groups are tolerated, although a slightly increased reaction temperature was necessary for the morpholine-substituted aryl bromide (3y-z). Pleasingly, the heterocyclic aryl bromides, 5-bromoindole and 4-bromothiazole, produced the corresponding products in 53-54\% yield (3aa-ab). Notably, the carbonylative cross-electrophile coupling can also be performed on more complex aryl bromides such as derivatives of an amino acid, $\delta$-tocopherol, a furanose, and a pyranose (3ac-af).

Control experiments showed that no carbonylative cross-coupling product 3a was formed in the absence of either $\mathrm{Pd}(\mathrm{acac})_{2}$ or $\left(\mathrm{PPh}_{3}\right)_{3} \mathrm{RhCl}$ (Table 3$)$, In the absence of either $\mathrm{Pd}(\mathrm{acac})_{2}$ or $\mathrm{CO}$, no conversion of the starting materials $1 \mathbf{a}$ and $2 \mathbf{a}$ was observed. However, in the presence of $\mathrm{Pd}(\mathrm{acac})_{2}$ and CO consumption of both aryl bromide and aryl triflate was observed although the desired product was not formed in the absence of $\left(\mathrm{PPh}_{3}\right)_{3} \mathrm{RhCl}$. Taken together these experiments could indicate that the palladium catalyst is responsible for activating both electrophiles, but that the presence of $\mathrm{CO}$ is required for the activation to take place. ${ }^{11-13}$

In summary, we have demonstrated the first method for carbonylative cross-electrophile coupling with carbon monoxide gas. The use of cooperative $\mathrm{Pd} / \mathrm{Rh}$ catalysis
Table 3. Control Experiments

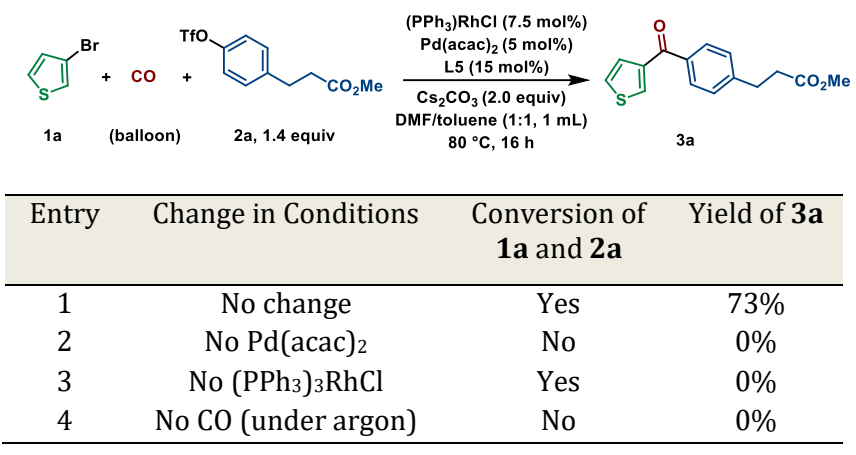

enables carbonylative coupling between aryl bromides and aryl triflates, thereby avoiding the use of nucleophilic metal-based coupling partners with limited stability and accessibility. Both aryl bromides and the phenols used as precursors for aryl triflates are abundant compounds making them convenient coupling partners. Only a small excess of the aryl triflate is needed to achieve high selectivity for the carbonylative cross-coupling. Remarkably, unlike previous carbonylative cross-electrophile coupling reactions, the method does not require the addition of a stoichiometric metal reductant, possibly due to carbon monoxide gas serving as a reductant. The results presented here lays the foundation for future carbonylative cross-electrophile coupling reactions that avoids the formation of stoichiometric metal waste.

\section{ASSOCIATED CONTENT}

Supporting Information. This material is available free of charge via the Internet at http://pubs.acs.org. Experimental procedures along with characterization data and copies of ${ }^{1} \mathrm{H},{ }^{13} \mathrm{C}$ and ${ }^{19} \mathrm{~F}$ NMR spectra (PDF).

\section{AUTHOR INFORMATION}

\section{Corresponding Author}

* Zhong Lian: lianzhong@scu.edu.cn

* Søren Kramer: sokr@kemi.dtu.dk

\section{Author Contributions}

$\$$ These authors contributed equally.

\section{ACKNOWLEDGMENT}

This work is supported by National Natural Science Foundation of China (21901168), "1000-Youth Talents Plan”, Sichuan Science and Technology Program (2021YJ0395) and "1.3.5 project for disciplines of excellence, West China Hospital, Sichuan University". S.K. is deeply appreciative of financial support from the Lundbeck Foundation (grant no. R250-20171292), the Independent Research Fund Denmark (grant no. 0171-00018B), and the Villum Foundation (grant no. 35812).

\section{REFERENCES}

(1) (a) Luque-Ortega, J. R.; Reuther, P.; Rivas, L.; Dardonville, C., New benzophenone-derived bisphosphonium salts as leishmanicidal leads targeting mitochondria through inhibition of respiratory complex II. J. Med. Chem. 2010, 53, 1788-98; (b) Maria Letizia, B.; Stefania, F.; Angela, R.; Laura, D. L.; Maria, Z.; Anna- 
Maria, M.; Zeger, D.; Myriam, W.; Alba, C., Pharmacophore-Based Design of HIV-1 Integrase Strand-Transfer Inhibitors. J. Med. Chem. 2005, 48, 7084-7088; (c) Vooturi, S. K.; Cheung, C. M.; Rybak, M. J.; Firestine, S. M., Design, synthesis, and structureactivity relationships of benzophenone-based tetraamides as novel antibacterial agents. J. Med. Chem. 2009, 52, 5020-31.

(2) (a) Barnard, C. F. J., Palladium-Catalyzed Carbonylation-A Reaction Come of Age. Organometallics 2008, 27, 5402-5422; (b) Brennfuhrer, A.; Neumann, H.; Beller, M., Palladium-catalyzed carbonylation reactions of aryl halides and related compounds. Angew. Chem. Int. Ed. 2009, 48, 4114-33; (c) Friis, S. D.; Lindhardt, A. T.; Skrydstrup, T., The Development and Application of TwoChamber Reactors and Carbon Monoxide Precursors for Safe Carbonylation Reactions. Acc. Chem. Res. 2016, 49, 594-605; (d) Grigg, R.; Mutton, S. P., Pd-catalysed carbonylations: versatile technology for discovery and process chemists. Tetrahedron 2010, 66, 5515-5548; (e) Li, Y.; Hu, Y.; Wu, X.-F., Non-noble metalcatalysed carbonylative transformations. Chem. Soc. Rev. 2018, 47, 172-194; (f) Peng, J. B.; Wu, F. P.; Wu, X. F., First-Row Transition-Metal-Catalyzed Carbonylative Transformations of Carbon Electrophiles. Chem. Rev. 2019, 119, 2090-2127; (g) Peng, J.-B.; Geng, H.-Q.; Wu, X.-F., The Chemistry of CO: Carbonylation. Chem 2019, 5, 526-552; (h) Wu, X. F.; Neumann, H.; Beller, M., Synthesis of heterocycles via palladium-catalyzed carbonylations. Chem. Rev. 2013, 113, 1-35; (i) Wu, X.-F.; Helfried, N.; Beller, M., Palladium-catalyzed carbonylative coupling reactions between $\mathrm{Ar}-\mathrm{X}$ and carbon nucleophiles. Chem. Soc. Rev. 2011, 40, 4986-5009; (j) Zhang, F.; Xiao, Y.-L.; Zhang, X., Transition-Metal (Cu, Pd, Ni)Catalyzed Difluoroalkylation via Cross-Coupling with Difluoroalkyl Halides. Acc. Chem. Res. 2018, 51, 2264-2278; (k) Zhu, C.; Liu, J.; Li, M. B.; Backvall, J. E., Palladium-catalyzed oxidative dehydrogenative carbonylation reactions using carbon monoxide and mechanistic overviews. Chem. Soc. Rev. 2020, 49, 341-353.

(3) (a) Cherney, A. H.; Kadunce, N. T.; Reisman, S. E., Enantioselective and Enantiospecific Transition-Metal-Catalyzed CrossCoupling Reactions of Organometallic Reagents To Construct C-C Bonds. Chem. Rev. 2015, 115, 9587-652; (b) Poremba, K. E.; Dibrell, S. E.; Reisman, S. E., Nickel-Catalyzed Enantioselective Reductive Cross-Coupling Reactions. ACS Catal. 2020, 10, 82378246; (c) Weix, D. J., Methods and Mechanisms for CrossElectrophile Coupling of $\mathrm{Csp}(2)$ Halides with Alkyl Electrophiles. Acc. Chem. Res. 2015, 48, 1767-1775.

(4) (a) Amatore, M.; Gosmini, C., Direct method for carboncarbon bond formation: the functional group tolerant cobaltcatalyzed alkylation of aryl halides. Chem. Eur. J. 2010, 16, 584852; (b) Czaplik, W. M.; Mayer, M.; Jacobi von Wangelin, A., Domino iron catalysis: direct aryl-alkyl cross-coupling. Angew. Chem. Int. Ed. 2009, 48, 607-10; (c) Krasovskiy, A.; Duplais, C.; Lipshutz, B. H., Zn-Mediated, Pd-Catalyzed Cross-Couplings in Water at Room Temperature Without Prior Formation of Organozinc Reagents. J. Am. Chem. Soc. 2009, 131, 15592-1593; (d) Wang, X.; Ma, G.; Peng, Y.; Pitsch, C. E.; Moll, B. J.; Ly, T. D.; Wang, X.; Gong, H., NiCatalyzed Reductive Coupling of Electron-Rich Aryl Iodides with Tertiary Alkyl Halides. J. Am. Chem. Soc. 2018, 140, 14490-14497; (e) Yu, X.; Yang, T.; Wang, S.; Xu, H.; Gong, H., Nickel-Catalyzed Reductive Cross-Coupling of Unactivated Alkyl Halides. Org. Lett. 2011, 13, 2138-2141.

(5) For examples without a stiochiometric metal reductant, see: (a) Jiao, K. J.; Liu, D.; Ma, H. X.; Qiu, H.; Fang, P.; Mei, T. S., NickelCatalyzed Electrochemical Reductive Relay Cross-Coupling of Alkyl Halides to Aryl Halides. Angew. Chem. Int. Ed. 2020, 59, 6520-6524; (b) Perkins, R. J.; Hughes, A. J.; Weix, D. J.; Hansen, E. C., Metal-Reductant-Free Electrochemical Nickel-Catalyzed Couplings of Aryl and Alkyl Bromides in Acetonitrile. Org. Process Res. Dev. 2019, 23, 1746-1751; (c) Perkins, R. J.; Pedro, D. J.; Hansen, E. C., Electrochemical Nickel Catalysis for $\mathrm{Sp}(2)-\mathrm{Sp}(3)$ CrossElectrophile Coupling Reactions of Unactivated Alkyl Halides. Org. Lett. 2017, 19, 3755-3758; (d) Truesdell, B. L.; Hamby, T. B.; Sevov, C. S., General C(sp(2))-C(sp(3)) Cross-Electrophile Cou- pling Reactions Enabled by Overcharge Protection of Homogeneous Electrocatalysts. J. Am. Chem. Soc. 2020, 142, 5884-5893; (e) Zhang, P.; Le, C. C.; MacMillan, D. W., Silyl Radical Activation of Alkyl Halides in Metallaphotoredox Catalysis: A Unique Pathway for Cross-Electrophile Coupling. J. Am. Chem. Soc. 2016, 138, 8084-7.

(6) (a) Ackerman, L. K.; Lovell, M. M.; Weix, D. J., Multimetallic catalysed cross-coupling of aryl bromides with aryl triflates. $\mathrm{Na}$ ture 2015, 524, 454-7; (b) Huang, L.; Ackerman, L. K. G.; Kang, K.; Parsons, A. M.; Weix, D. J., LiCl-Accelerated Multimetallic CrossCoupling of Aryl Chlorides with Aryl Triflates. J. Am. Chem. Soc. 2019, 141, 10978-10983; (c) Kang, K.; Huang, L.; Weix, D. J., Sulfonate Versus Sulfonate: Nickel and Palladium Multimetallic Cross-Electrophile Coupling of Aryl Triflates with Aryl Tosylates. J. Am. Chem. Soc. 2020, 142, 10634-10640; (d) Olivares, A. M.; Weix, D. J., Multimetallic Ni- and Pd-Catalyzed Cross-Electrophile Coupling To Form Highly Substituted 1,3-Dienes. J. Am. Chem. Soc. 2018, 140, 2446-2449.

(7) (a) Wotal, A. C.; Weix, D. J., Synthesis of Functionalized Dialkyl Ketones from Carboxylic Acid Derivatives and Alkyl Halides. Org. Lett. 2012, 14, 1476-1479; (b) Wu, F.; Lu, W.; Qian, Q.; Ren, Q.; Gong, H., Ketone Formation via Mild Nickel-Catalyzed Reductive Coupling of Alkyl Halides with Aryl Acid Chlorides. Org. Lett. 2012, 14, 3044-3047; (c) Yin, H.; Zhao, C.; You, H.; Lin, K.; Gong, $\mathrm{H}$., Mild ketone formation via Ni-catalyzed reductive coupling of unactivated alkyl halides with acid anhydrides. Chem. Commun. 2012, 48, 7034-6; (d) Cherney, A. H.; Kadunce, N. T.; Reisman, S. E., Catalytic Asymmetric Reductive Acyl Cross-Coupling: Synthesis of Enantioenriched Acyclic alpha,alpha-Disubstituted Ketones. J. Am. Chem. Soc. 2013, 135, 7442-7445; (e) Zhao, C.; Jia, X.; Wang, X.; Gong, H., Ni-catalyzed reductive coupling of alkyl acids with unactivated tertiary alkyl and glycosyl halides. J. Am. Chem. Soc. 2014, 136, 17645-51; (f) Jia, X.; Zhang, X.; Qian, Q.; Gong, H., Alkylaryl ketone synthesis via nickel-catalyzed reductive coupling of alkyl halides with aryl acids and anhydrides. Chem. Commun. 2015, 51, 10302-5; (g) Ni, S.; Zhang, W.; Mei, H.; Han, J.; Pan, Y., NiCatalyzed Reductive Cross-Coupling of Amides with Aryl Iodide Electrophiles via C-N Bond Activation. Org. Lett. 2017, 19, 25362539; (h) Ding, D.; Wang, C., Nickel-Catalyzed Reductive Electrophilic Ring Opening of Cycloketone Oxime Esters with Aroyl Chlorides. ACS Catal. 2018, 8, 11324-11329; (i) Lin, T.; Mi, J.; Song, L.; Gan, J.; Luo, P.; Mao, J.; Walsh, P. J., Nickel-Catalyzed Desymmetrizing Cross-Electrophile Coupling of Cyclic Meso-Anhydrides. Org. Lett. 2018, 20, 1191-1194; (j) Zhao, X.; Tu, H. Y.; Guo, L.; Zhu, S.; Qing, F. L.; Chu, L., Intermolecular selective carboacylation of alkenes via nickel-catalyzed reductive radical relay. Nat. Commun. 2018, 9, 3488; (k) Pan, F. F.; Guo, P.; Li, C. L.; Su, P.; Shu, X. Z., Enones from Acid Fluorides and Vinyl Triflates by Reductive Nickel Catalysis. Org. Lett. 2019, 21, 3701-3705; (l) Shi, R.; Hu, X., From Alkyl Halides to Ketones: Nickel-Catalyzed Reductive Carbonylation Utilizing Ethyl Chloroformate as the Carbonyl Source. Angew. Chem. Int. Ed. 2019, 58, 7454-7458; (m) Wang, J.; Cary, B. P.; Beyer, P. D.; Gellman, S. H.; Weix, D. J., Ketones from NickelCatalyzed Decarboxylative, Non-Symmetric Cross-Electrophile Coupling of Carboxylic Acid Esters. Angew. Chem. Int. Ed. 2019, 58, 12081-12085; (n) Wang, J.; Hoerrner, M. E.; Watson, M. P.; Weix, D. J., Nickel-Catalyzed Synthesis of Dialkyl Ketones from the Coupling of N-Alkyl Pyridinium Salts with Activated Carboxylic Acids. Angew. Chem. Int. Ed. 2020, 59, 13484-13489; (o) Wang, L.; Wang, C., Nickel-Catalyzed Three-Component Reductive Alkylacylation of Electron-Deficient Activated Alkenes. Org. Lett. 2020, 22, 8829-8835; (p) Yang, F.; Ding, D.; Wang, C., Nickel-Catalyzed Directed Cross-Electrophile Coupling of Phenolic Esters with Alkyl Bromides. Org. Lett. 2020, 22, 9203-9209; (q) Zhuo, J.; Zhang, Y.; Li, Z.; Li, C., Nickel-Catalyzed Direct Acylation of Aryl and Alkyl Bromides with Acylimidazoles. ACS Catal. 2020, 10, 3895-3903.

(8) One method with a metallic carbon monoxide surrogate, $\mathrm{Fe}(\mathrm{CO})_{5}$, has been reported: Wotal, A. C.; Ribson, R. D.; Weix, D. J., Stoichiometric Reactions of Acylnickel(II) Complexes with Elec- 
trophiles and the Catalytic Synthesis of Ketones. Organometallics 2014, 33, 5874-5881.

(9) One method using ethyl chloroformate as carbon monoxide surrogate has been reported: Shi, R.; Hu, X., From Alkyl Halides to Ketones: Nickel-Catalyzed Reductive Carbonylation Utilizing Ethyl Chloroformate as the Carbonyl Source. Angew. Chem. Int. Ed. 2019, 58, 7454-7458.

(10) For reviews on cooperative metal catalysis, including Pd/Rh catalysis, see: (a) Kim, U. B.; Jung, D. J.; Jeon, H. J.; Rathwell, K.; Lee, S. G., Synergistic Dual Transition Metal Catalysis. Chem. Rev. 2020, 120, 13382-13433; (b) Lorion, M. M.; Maindan, K.; Kapdi, A. R.; Ackermann, L., Heteromultimetallic catalysis for sustainable organic syntheses. Chem. Soc. Rev. 2017, 46, 7399-7420.

(11) The reductant for the catalytic process is not clear at this point. The need for $\mathrm{CO}$ to be present for conversion to take place indicates that $\mathrm{CO}$ could be the reductant for palladium, for example by reductive elimination of a phosgene equivalent (see reference 12). Alternatively, DMF can serve as reductant; however, catalytic turnover is also observed in other solvents (Table 2).

(12) (a) Baig, S.; Richard, B.; Serp, P.; Mijoule, C.; Hussein, K.; Guihéry, N.; Barthelat, J.-C.; Kalck, P., Synthesis and Theoretical Study of a Series of Dipalladium(I) Complexes Containing the $\mathrm{Pd}_{2}(\mu-\mathrm{CO})_{2}$ Core. Inorg. Chem. 2006, 45, 1935-1944; (b) Belli Dell'Amico, D.; Calderazzo, F.; Zandona, N., Formation of palladium(II) and palladium(I) carbonyl halo complexes. Inorg. Chem. 1984, 23, 137-140; (c) Levesque, T. M.; Kinney, R. G.; Arndtsen, B. A., A palladium-catalyzed $\mathrm{C}-\mathrm{H}$ functionalization route to ketones via the oxidative coupling of arenes with carbon monoxide. Chem. Sci. 2020, 11, 3104-3109; (d) Ragaini, F.; Larici, H.; Rimoldi, M.; Caselli, A.; Ferretti, F.; Macchi, P.; Casati, N., Mapping Palladium Reduction by Carbon Monoxide in a Catalytically Relevant System. A Novel Palladium(I) Dimer. Organometallics 2011, 30, 2385 2393; (e) Stromnova, T. A.; Vargaftik, M. N.; Moiseev, II, Mechanism of reaction of palladium(II) carboxylates with carbon monoxide in nonaqueous media. J. Organomet. Chem. 1983, 252, 113120.

(13) One example of an Fe/Co-catalyzed carbonylative homocoupling of aryl iodides without a metal reductant exists: Brunet, J. J.; Taillefer, M., Bimetallic catalysis: Synthesis of benzophenones through carbonylation of aryl iodides catalysed $\mathrm{Fe}(\mathrm{CO})_{5}-\mathrm{Co}_{2}(\mathrm{CO})_{8}$ Systems. J. Organomet. Chem. 1990, 384, 193-197. 


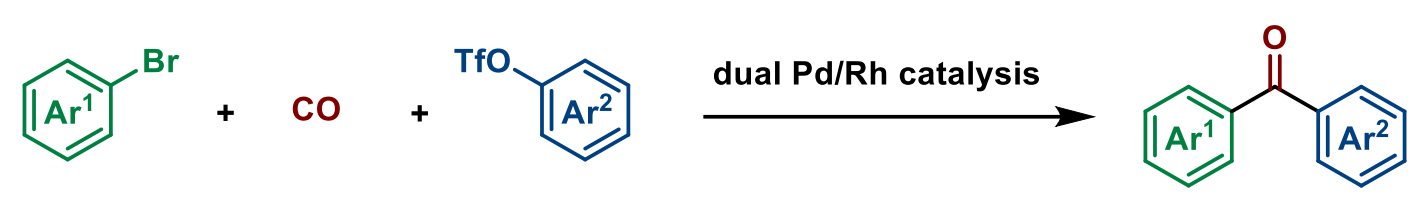

- Carbon monoxide gas as carbonyl source

- No stoichiometric metal reductant required 